There is a wealth of florid clinical material of a kind seldom seen nowadays in Britain, there are remarkable geographical variations in disease which may, as F. Avery Jones ${ }^{3}$ has emphasized in the field of alimentary cancer, ${ }^{4}$ throw new light on common diseases at home, and there is the stimulating challenge of adapting the provision of medical care to circumstances and resources that differ greatly from our own. The old mistake that all that is required is to transplant British training and practice virtually unaltered is happily giving way to more realistic appreciation of what is required. The Delhi Conference underlined the importance of relating both medical education and medical practice to the needs and state of development of the community.

In this context the efforts of the Commonwealth Medical Association $^{5}$ and of the B.M.A's Overseas Affairs Committee ${ }^{6}$ to strengthen the links between Commonwealth doctors are timely. There is no substitute to discussing a difficult problem face to face and with first-hand knowledge, and the fostering of cross-postings in medical schools and hospitals, teaching attachments, and individual visits by doctors can only be beneficial. Coming at a time when the British Government is seeking to treble the tuition fees of overseas students $^{7}$ and when through lack of funds the British Council ${ }^{8}$ finds itself compelled to cut back its valuable contribution, these statements of professional determination to keep alive the free flow of doctors across national frontiers are doubly to be welcomed. In Marquis's words : "If we confine ourselves to the problems of medicine in the United Kingdom it will be to the detriment of both ourselves and our friends in the East." This applies with equal force throughout the Commonwealth, and indeed the whole world.

\section{Glycosuria in Pregnancy}

Women found to have glycosuria during pregnancy may receive a variety of advice. At one extreme is the opinion that pregnancy is a diabetogenic stimulus, at the other the more popular view at present that such glycosuria is nearly always innocent.

One difficulty is that the reported incidence of glycosuria during pregnancy ranges from $3 \%$ to as high as $90 \%$ after a meal. ${ }^{1}$ This suggests that attention should be paid to the finding of glycosuria itself before opinions are expressed on its significance. For example, it is already known that the likelihood of finding glycosuria increases after the woman has had a carbohydrate meal, with the duration of pregnancy, ${ }^{2}$ and with the testing of repeated urine samples. In addition, methods of detecting glycosuria have improved, and there are now precise quantitative techniques for estimating glucose itself.

The careful investigations reported by Dr. J. Fine at page 205 of the B.M.7. this week will help to clear up some of the current confusion as well as providing a rational means of interpreting glycosuria of pregnancy. In addition to investigating over 2,000 pregnant women he also compared them with a control population on which he has previously reported. ${ }^{3} \mathrm{He}$ used Clinistix as a screening test for glycosuria and chose a glucose-oxidase technique as suitable for the

\footnotetext{
${ }^{1}$ Richardson, R., and Bitter, R. S., Amer. F. Obstet. Gynec., 1932, 24,

2 Joslin, E. P., Root, H. F., White, P., and Marble, A., Treatment of

- Fine, J., Brit. med. Э., 1965, 1, 1209.
}

study of large numbers of urines. In the normal population he found $91 \%$ of people excreted between 1 and $15 \mathrm{mg}$. glucose per $100 \mathrm{ml}$. urine and $9 \%$ over $15 \mathrm{mg}$. per $100 \mathrm{ml}$. In 1,000 pregnant women the overall distribution was similar, but there was an increase both in the number of urines with low levels of glucose $(0-1 \mathrm{mg}$. per $100 \mathrm{ml}$.) and in those with glucose levels over $15 \mathrm{mg}$. per $100 \mathrm{ml}$. Glucose tolerance tests were carried out in 374 pregnant women with glycosuria, and the results showed that $94 \%$ had renal glycosuria, $5 \%$ a lag type of curve, and only $1 \%$ a diabetic glucose tolerance. In the total series of 2,547 pregnant women only three cases of diabetes were detected, which, together with four already known, gave a figure of $0.28 \%$, approximately one-sixth the incidence of diabetes in the control population.

When more than one specimen of urine was tested the detection of glycosuria rose, and observations throughout the 24 hours showed that there were much wider fluctuations in output of glucose in pregnancy than in the controls. Peak values could often be related to intake of food, and when a series of 50 women were investigated after administration of $50 \mathrm{~g}$. glucose no less than $90 \%$ were found to have positive Clinistix tests as compared with only $20 \%$ of the controls. Quantitative tests gave similar results. Since such a large proportion of pregnant women can be shown to have glycosuria under carefully standardized conditions, it is obviously illogical to subject them to time-consuming glucose tolerance tests because of the chance finding of glucose in a random specimen of urine. Glycosuria might therefore be regarded as a normal accompaniment of pregnancy.

What then is to be done to detect the rare patient who is a true diabetic? Fine suggests that a single blood-sugar determination should be made one hour after a carbohydrate meal or glucose drink, and that this might well be combined with other routine investigations carried out in antenatal clinics. The added burden of blood-sugar estimations could be readily borne in automated laboratories, and would be more than offset by the reduction in the present practice of carrying out glucose tolerance tests in pregnant women who are found to have glycosuria.

\section{Strokes and Fits}

It is a curious paradox that the more we know about strokes the more we realize how inaccurate clinical diagnosis can be. Small haemorrhages mimic massive infarcts-and vice versa. Peripheral cerebral embolism often reflects proximal arterial disease. Add to this the concept of relative ischaemia and infarction without complete occlusion and it is not surprising that the diagnosis "cerebral thrombosis" is now made with great caution in the absence of arteriographic or necropsy evidence.

Recurrent strokes present a similar diagnostic problem. Has the patient had a further haemorrhage or embolism in exactly the same site, or has an area of brain which was rendered partially ischaemic by the original attack been deprived of further function by some temporary lowering of blood flow? Elsewhere in this issue of the B.M.F. Dr. W. Fine (p. 199), reporting on elderly patients, draws attention to another possible explanation in some cases. It is often taught that occlusive vascular disease rarely causes fits, except perhaps at the onset of the ischaemia. In practice this is found not to be strictly true. Though focal convulsions 
and resulting hemiplegia should always raise the suspicion of progressive cerebral disease such as neoplasia until proved otherwise, if there has been a cerebrovascular accident there is an area of damaged brain capable of acting as an epileptogenic zone and of producing focal fits. These may be followed by post-epileptic paralysis, and it might thus appear that a further vascular accident has occurred. This is in fact the one type of "stroke" which could be prevented by the simple means of prescribing anticonvulsants.

Fine also draws attention to the possibility that some cases of post-hemiplegic pain-usually as intractable a condition as post-herpetic neuralgia-may be due to epileptic discharges, and, if so, preventable by anticonvulsants. This is a valuable idea, and shows how important it is by careful history-taking to define the characteristics of the painwhether it is episodic and whether associated with any motor symptoms on the affected side. An electroencephalographic focus corresponding to the area affected would give additional support to the diagnosis, and treatment with anticonvulsants may be dramatically successful.

Great diagnostic caution is needed here, however. Cerebral tumours, whether primary or metastatic, can sometimes present as an acute hemiplegia and mimic a stroke in almost every way, but in an elderly patient who has previously had a stroke the possibility of post-hemiplegic motor or sensory epilepsy should be borne in mind. Though the condition may be uncommon, it can be amenable to simple treatment.

\section{Referring the Patient}

Increasing specialization in medicine has led to a problem that has sometimes put a strain on relations between general practitioner and specialist. It arises when a specialist finds that the patient has some condition, other than that for which he was originally referred, which would need the attentions of other specialists for investigation and perhaps treatment. The easiest and quickest course may seem to be for the first specialist directly to invite one or more of his hospital colleagues to take charge of the patient. In practice a doctor has sometimes sent his patient for a consultant opinion on, say, a chest condition, and in due course received with this opinion the information that the patient has been referred to a surgeon for a hernia, another surgeon for a cataract, and a dermatologist for eczema. This procedure is apt to bewilder both patient and family doctor, and there can be serious objections to it, not least from the point of view of the patient's welfare. With this in mind the Council of the B.M.A. has recently approved a recommendation of its Central Ethical Committee on the subject of acceptance of patients by specialists. The proposal will now go forward to the Representative Body at Bristol.

The existing ethical policy on acceptance of patients states:

"A practitioner in any form of specialist practice should not, except in circumstances stated below, accept a patient for examination and advice except on a reference from a general practitioner, or from another specialist, which should only be with the general practitioner's knowledge.

"The specialist should ensure that the true position is ascertained at the time an appointment is booked and should ask that an introductory letter be brought."

Exceptions included emergencies, consultations in venereology, and patients who were overseas visitors with no family doctor in Britain.
The sense of the new policy is that only so long as a specialist is himself concerned with the management of the patient may he obtain further opinions from his colleagues without first consulting the general practitioner. If the patient has a chest complaint the opinions of a radiologist or another chest specialist could be sought without reference back. Should the specialist decide that the patient has a condition which is outside his own field he must refer him back to his general practitioner. The specialist may not himself refer the patient to a colleague.

When the proposals were debated in Council (Supplement, 14 January, p. 9) some of the consultants present suggested that this procedure would waste time for both patient and doctor. The exceptions included in the proposals should prevent this. For example, in an emergency, or if the patient would be seriously inconvenienced, the code may be waived provided the specialist informs the general practitioner at the earliest opportunity of the action that he has taken.

If the Representative Body approves these proposals there will be no startling changes in relations between general practitioners and specialists. They have got on well together in the past by practising professional courtesy, and no one supposes that courtesy will diminish in the future. Nevertheless, support for the proposals could be a welcome sign that the profession as a whole recognizes the value to patients of a family doctor whose responsibility does not stop at the hospital gates.

\section{Influenza}

Influenza epidemics can be predicted with reasonable confidence only when a new subtype of the virus makes its appearance. In the absence of this event forecasts must be very tentative but may be attempted on the basis of the incidence of the disease in previous years, on the study of antigenic variation of the virus, and on the immune status of human populations as shown by serological methods. Experience in recent years indicates that when the disease is not pandemic it is often restricted to particular geographical areas.

Since 1957, when the A2 (Asian) subtype of influenza appeared, epidemics have been limited to certain countries or geographical areas during each particular outbreak. In Great Britain influenza has been prevalent during most winters, mainly in the form of scattered outbreaks but occasionally reaching epidemic proportions, as, for instance, in 1959 and 1961 (influenza A2) and in 1962 (influenza B). During the winter of 1965-6 outbreaks of influenza A2 and B were recorded in many areas in this country. No influenza has been reported here during the present winter, but since last November outbreaks of varying extent have been observed in Czechoslovakia, Bulgaria, Italy, and the U.S.S.R. Influenza A2 and B viruses associated with these outbreaks are closely related to strains prevalent in previous years. Both epidemiological and virological evidence suggest, therefore, that the incidence of influenza is unlikely to be high in Britain this winter. Consequently there seems to be no indication now for extensive use of influenza vaccines. But vaccination may be of value to protect patients at special risk, such as those with chronic debilitating diseases. Inactivated vaccines containing current influenza $A 2$ and $B$ antigenic variants are available and should confer some protection. 